\title{
The Effect of Naturism on Body Image and Interoceptive Awareness
}

\author{
Robert J Hargreaves \\ Birkbeck College, University of London
}


Research considering the benefits of Naturism on body image recently re-emerged after decades of neglect. The present study continued prior work assessing positive body image and went further adding an instrument used to assess Eating Disorder treatment efficacy expecting to benchmark naturists with very low symptomatology scores. Self-report Interoceptive testing was also employed to consider neurological underpinnings and benefits of their exceptional resilience. 43 naturists (37 male), average age 57 , and 36 controls ( 21 male), average age 38 , British origin, participated online. Utilizing the Body Appreciation Scale 2 and The Eating Disorder Examination Questionnaire, naturists consistently, significantly achieved higher positive, and lower negative body image scores across all measures. Naturist results on the Multidimensional Assessment of Interoceptive Awareness 2 across all dimensions were also persistently higher than controls. Naturist results confirm their position as a unique population demonstrating exceptionally high negative body image resilience, this coupled with potential advantageous neurological benefits that with further investigation could lead to naturism becoming a proactive mind-body therapy to help prevent eating disorders. Comprehensive future philosophical, phenomenological and longitudinal research options were also put forward. 


\section{Introduction}

\section{A Body Image Dissatisfaction Epidemic}

Body and appearance dissatisfaction in the Western world have reached epidemic proportions with general population estimates of between $23-56 \%$ for women, and $15-43 \%$ for men, leading to the term 'normative discontent,' meaning it has become normal for the general population to feel dissatisfied with their body (Fallon, Harris \& Johnson, 2014). Eating disorders (ED) are psychiatric conditions with a combination of biological, psychological and sociocultural influences (Culbert, Racine \& Klump, 2015). Genetic predisposition of ED based on monozygotic twin heritability studies estimates anorexia nervosa at between $28 \%$ and $58 \%$ leaving a sizeable contribution attributable to environmental influences (Thornton, Mazzeo \& Bulik, 2010). Metaanalysis of ED found lifetime prevalence rising but averaging at $8.4 \%$ for women, and $2.2 \%$ for men (Galmiche, Déchelotte, Lambert \& Tavolacci, 2019). Body dissatisfaction is pathognomonic of ED with overlapping symptoms, because of this and the high level of associated environmental causality it is important to find ways to address negative social and cultural influences to enable the strive for proactive solutions (Smolak \& Cash, 2011; Tylka \& Wood-Barcalow, 2015).

The Victorians popularised corsets and tiny waistlines, but previously few examples exist of slender body ideals, thinness was considered ugly and unfortunate (p.4-5, Seid, 1994). During the $20^{\text {th }}$ century overweight bodies became associated with low morality and personal inadequacy, symbolically vigilant management of body image became equated to level of personal order (p.190-193, Bordo, 1993). Thin female and muscular male archetypes have become engrained in modern western society, linking to success, happiness, and social acceptability. Contrastingly being 
overweight is viewed as unattractive and non-conformance can lead to negative social outcomes (Klaczynski, Goold \& Mudry, 2004). Modern society has many negative body image influences, some with good intention that can create negative side-effects such as government obesity campaigns (Puhl, Peterson \& Luedicke, 2013), and the connected diet industry (Furnham \& Greaves, 1994). Developmental studies found television (Clark \& Tiggemann, 2007), internet, and social media use (Tiggemann \& Slater, 2014) led to internalisation of thin ideals and dieting behaviour, meta-reviews detail the same for adults (Groesz, Levine \& Murnen, 2002; Barlett, Vowels, \& Saucier, 2008). In less developed countries thin bodies can represent poverty, malnutrition and disease (McLaren, 2007), but anthropologic studies have found after only one-month introduction of television can lead to attempted emulation of bodies viewed (Becker, 2012; Boothroyd et al., 2016). Cultural transmission can also occur following emigration with cross cultural research finding that Asian women moving to Kenya rated larger bodies most desirable but others moving to England preferred slender figures (Furnham \& Alibhai, 1983).

Social psychological theories explain social transmission of behaviour, attitudes and ideals covering parental, peer and media exposure. Social comparison theory suggests individuals seek accurate, objective evaluations of their attitudes and abilities. Self-evaluations are either, upward when viewing others as scoring higher on an attribute, or downward comparisons when they score lower (p.162, Suls \& Wheeler, 2013). Self-discrepancy theory proposes motivations and emotional vulnerabilities are a product of discrepancies in self-focussed belief patterns. To improve well-being and reduce distress individuals are driven to reduce the gap between the perceived self, the ideal self, and the ought self; the latter whereby the person feels obliged to align to fit in (Higgins, 1987). Group socialisation theory 
(Levine, Resnick \& Higgins, 1993) covers peer transmission in direct contact and can cover many areas of life from games in children and language (Harris, 1995), through to development of normative beliefs about bullying (Almeida, Correia \& Marinho, 2009). Social learning theory is broader and combines behaviourist thinking from the conditioning domain with mediation processes and adaptation of behaviour through observational learning (Bandura, 1962). The bobo doll experiment (Bandura, 1961) demonstrated children observing before mimicking aggressive behaviour. Children's developing body concepts integrate parental body attitudes, with negativity having the strongest effect (Levy, 1932). Mediation processes influence the likelihood of replication including salience and memory of observations, the ability to re-enact, and perceived rewards and punishment (Bandura, 1962). These theories can explain socially learned behaviour and form part of the hypothesis of this study.

Body image can be measured as positive or negative, but is not a single continuum, negativity and shame were historically the focus of research, but positive instruments have been developed to help understand resilience and highlight populations with potentially transferable benefits (Striegel-Moore \& Cachelin, 1999). Psychometric questionnaires chosen for this study were the Body Appreciation Scale (BAS-2) to assess body acceptance, respect and rejection of media prescribed ideals (Tylka \& Wood-Baraclow, 2015), alongside the clinical Eating Disorder Examination Questionnaire (EDE-Q), covering shape and weight concern (Fairburn \& Beglin, 1994; Fairburn, 2008). 


\section{What is Naturism?}

Certain populations have proven to be more resilient to negative body image.

Naturism can be defined in simple terms as the practice of social non-sexual nudity. It can be practiced anywhere but most common are homes, clubs, beaches, or dedicated holiday resorts (British Naturism, 2019). According to the International Naturist Federation (INF; International Naturist Federation, n.d.) organised naturism began in 1893 in Essen, Germany with the objective of disseminating principles of natural health care, at the time this meant exposing the complete body to sun and air. Ungewitter (1913) in his nudity and culture book reported women were happier not feeling embarrassed about their bodies within naturist communities. The popularity of naturism is growing with up to a quarter of British people trying social nudity activities (West, 2018). Naturism has support from many governments in Europe and Scandinavia, most notably France where they promote benefits of respect for individual differences and body acceptance alongside collectivist benefits of spending time with family and friends in the most naturalistic environment possible (France, 2018a).

Quantitative and longitudinal research considering social nudity finds it can contribute to improved body self-concept in children and adults with no negative effects, family sexual liberalism was mirrored in the adolescent but not simple nudity (Okami, Olmstead, Abramson \& Pendleton, 1998; Story, 1979, 1984). Recently West (2018) found a significant association between time spent practicing naturism and body appreciation. West draws on research that exposure to non-idealised bodies leads to positive feedback about the self (Green, 2001; Re et al., 2011; Herbozo and Thompson, 2006). Given the challenging treatment resistance of ED (Halmi, 2013), 
alongside the aforementioned directive from world leading specialists to focus on prevention it is imperative to further West's work.

\section{The Interoceptive Link}

Interoception refers to the processing of signals originating in the body and their transmission to the brain, afferent feedback incorporates conscious and unconscious physiological state information that is used to maintain bodily functioning and homeostasis (Khalsa et al., 2018). Interoceptive sensations available to the preconscious emanate from unmyelinated free nerve endings and also play a role in affective and emotional perception (Berlucchi \& Aglioti, 2010; Garfinkel et al., 2016). Thirst and hunger sensations motivate acts of sustenance, distension of the bladder triggers conscious efferent muscle control to manage excretion, heartbeat can also be voluntarily brought into conscious awareness with varying individual levels of accuracy (Herbert, Muth, Pollatos \& Herbert, 2012).

Neuroanatomically the anterior cingulate cortex and somatotopically organised insula (Craig, 2004; Haggard, lannetti \& Longo, 2013), collectively known as the insular cortex, contain functional areas for sensorimotor, social-emotional and olfactogustatory processing (Kurth, Zilles, Fox, Laird \& Eickhoff, 2010). The insula is central to vicarious observational learning, prediction of feeling states employed in anticipating emotional events relating to the body, and interpreting emotion in others (Singer, Critchley \& Prueschoff, 2009).

Interoceptive performance is associated with alexithymia (Brewer, Cook \& Bird, 2016), anxiety, depression (Paulus \& Stein, 2010), and autism (Garfinkel et al., 2016). Extant literature recognises interoceptive deficits alongside body image 
distortion as central to ED (Skårderud, 2009), supported by both self-report testing, and in person assessment of sensitivity to visceral activity (Herbert \& Pallatos, 2014), also meta-reviews of associated neurocircuit abnormalities (Khalsa \& Lapidus, 2016). ED psychopathological symptoms, including impairments in emotional processing, both in the self and recognition in others, and body distortion can be linked to the insular cortex (p.137-138, Tsakiris \& De Preester, 2018). Perception of the bodily self is constructed from a multi-modal combination of visual exteroceptive, proprioceptive, and interoceptive sensory information (Tsakiris, 2017). Neuroimaging studies find viewing self-images of the body leads to significantly reduced insular cortex activation in anorexia nervosa patients compared to healthy controls (Gaudio \& Quattrocchi, 2008; Sachdev, Mondraty, Wen \& Gulliford, 2008). Non-clinical groups also demonstrated lower interoceptive performance correlated with self-objectification (Ainley \& Tsakiris, 2013). Tsakiris \& De Preester (2018) surmise that interoceptive processes may be downregulating as part of a coping strategy (p.175), this also aligns with Gaete \& Fuchs (2016) embodied defence hypothesis whereby subjective embodied emotion is suppressed leading individuals to experience their body as object. Collectively this suggests negative body attitudes may lead to exteroceptive modality dominance whilst combining inputs that integrate to create conscious attentional representations of the self.

Mind-body pursuits, including yoga (Daubenmier, 2005) meditation, ballet (Sze, Gyurak Yuan \& Levenson, 2010) and mindfulness (Hanley, Mehling \& Garland, 2017) lead to interoceptive ability improvement. Longitudinal studies demonstrate significant interoceptive neuroplasticity potential, following contemplative training (Bornemann, Herbert, Mehling \& Singer, 2015), yoga and meditation over 2-years (Mehling et al, 2014). Neuroimaging has also demonstrated right anterior insula 
thickening alongside reduced recruitment of visual pathways following meditational practice over time (Farb, Segal \& Anderson, 2013), highlighting the potential for activities that lead to interoceptive ability improvement to counter the aforementioned downregulation.

Although interoceptive ability can be measured clinically by comparing perceived versus actual bodily signal detection this study employed an entirely self-reported psychometric questionnaire, the Multidimensional Assessment of Interoceptive Awareness (MAIA-2; Mehling, Acree, Stewart, Silas \& Jones, 2018).

Recently Todd, Aspell, Barron \& Swami (2019) continued interoceptive ability investigation work on healthy British adults linking greater awareness to positive body image finding interoceptive ability significantly predicted body appreciation.

\section{The Present Study}

The present study aimed to build on and part replicate prior research establishing a significant relationship between naturism and positive body image (West, 2018), by adding a psychometric instrument commonly used to assess emerging ED treatments (Fairburn, 2008), thus for the first time to benchmark the naturist population along a negative body image spectrum for comparison with other groups, internal and external to the study.

Alongside confirming that naturist activity leads to body satisfaction, the study also assessed interoceptive awareness, assuming that a practice, in this case naturism, that results in positive body image outcomes will also lead to improved interoceptive ability (Todd et al., 2019). This additional line of enquiry if correct allows for inferences to be made about how positive effects of naturism manifest 
neurologically, and the potential for it to be considered as a therapeutic approach to mind-body integration (Mehling et al., 2012).

\section{Hypotheses}

The first hypothesis (H1) predicted higher levels of body appreciation (BAS-2) and lower levels of shape and weight concern on the EDE-Q in naturists compared to controls.

The second hypothesis $(\mathrm{H} 2)$ predicted interoceptive awareness for naturists would be significantly higher than controls on the MAIA-2 Noticing subscale that represents ability to sense signals from the body. $\mathrm{H} 2$ is formulated based on Tsakiris \& De Preester's (2018) interoceptive downregulation theory (p.175) and the embodied defence hypothesis (Gaete \& Fuchs, 2016), they posit that cross-modal balance between interoception and exteroception is mediated by denial and coping when making social body comparisons. In practice, naturists spend time in groups where downward comparison between bodies can be made according to social comparison theory (p.162, Suls \& Wheeler, 2013), they are in the presence of realistic body role models leading to visual, non-verbal, social transmission of body ideals, aligning with group socialization theory (Levine, Resnick \& Higgins, 1993), clothing may also distort interpretation of the bodily self during immediate self-other conscious comparison via any medium (Kim \& Damhorst, 2010) in line with self-discrepancy theory (Higgins, 1987).

The third hypothesis $(\mathrm{H} 3)$ predicted that associations between BAS-2 and MAIA-2 would all be positive, and they would be higher degree for naturists. Negative relationships were predicted for both shape and weight concern. The high-level 
nature of $\mathrm{H} 3$ allowed for post-hoc exploration of relationships between all body image instruments and MAIA dimensions.

\section{Methods}

\section{Design}

The experiment employed a between-group design; naturist vs control population independent variables and within-subject dependent variables (MAIA-2; BAS-2 \& EDE-Q). Between group comparison of means were conducted for $\mathrm{H} 1$ and $\mathrm{H} 2$. For $\mathrm{H} 3$ bivariate correlation was used to understand relationships between body image instruments and MAIA dimensions. Psychometric questionnaires were delivered standardised, and non-randomised to increase reliability (Boynton \& Greenhaigh, 2004).

\section{Participants}

The study comprised of 51 naturist participants whom were largely male (47 male and 5 female), their ages were between 21 and 74 years $(M=54.21$ years, SD = 11.96). There were 40 control participants ( 21 male and 19 female), age between 23 and 59 years $(M=34.89$ years, $S D=12.79)$. Body Mass Index $(B M I)$ based on selfreport height and weight ranged between 19.15 and 38.19 for naturists $(M=27.68$, $S D=4.35)$, between 16.47 and 51.85 for controls $(M=25.46, S D=6.61)$, this was on average as expected in the United Kingdom (NHS, 2019). Exclusion criteria of minimum age 18-years applied for all participants. Controls were screened for experience of prior naturist activity, none were found. Ethical approval was granted by Psychological Sciences Department, Birkbeck College, University of London. Naturists were volunteer sampled, recruited through online forum advertisement in 
conjunction with British Naturism, controls were opportunity sampled from friends and associates of the author. No motivations or interests were identified, no payments, benefits or incentives were made. The experiment was conducted online as part of a BSc Psychology with Neuroscience dissertation. Participants had no prior knowledge or training and were invited to take part in a mind-body experiment.

\section{Materials}

General Data Protection Regulations (European Parliament, 2018) guidelines were utilised to ensure compliance of data, and anonymity. Gorilla experimental testing platform was used throughout (Figure 1) and provided tabulated raw data for analysis.

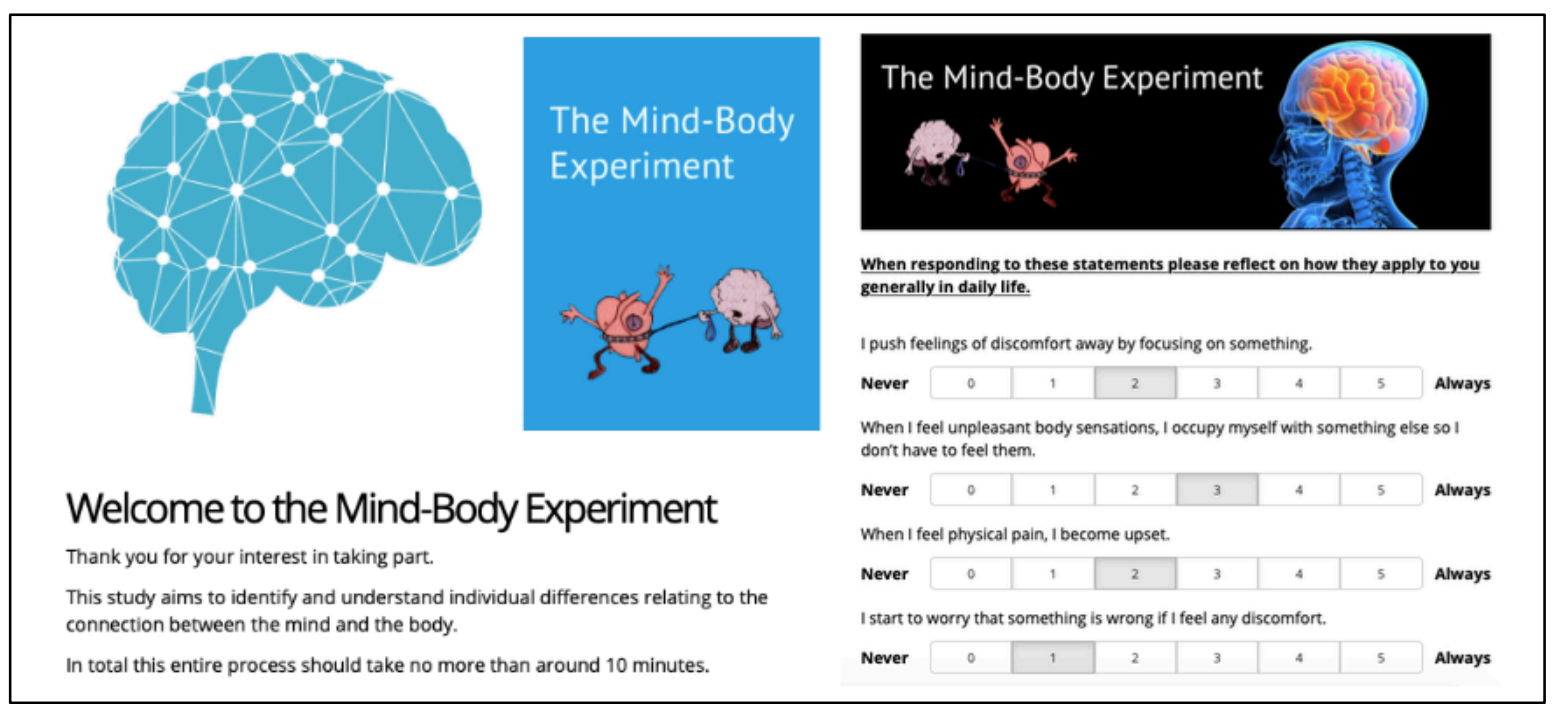

Figure 1. The Mind-Body Experiment, Gorilla Online Data Collection Platform

Microsoft Excel manipulated raw data. SPSS v.26, statistical analysis software application ran statistical tests. Three psychometric instruments relating to interoception, body image and ED were used. The Multidimensional Assessment of Interoceptive Awareness, version 2 (Appendix A), a revision of the MAIA adjusted to achieve higher convergent construct validity (Mehling et al., 2018). MAIA-2 breaks 
down into 8 subscales. The Noticing subscale reports awareness of bodily sensations; Not Distracting reports ability to not be distracted or to ignore sensations of discomfort or pain; Not Worrying reports tendency not to feel emotional distress or worry with sensations of discomfort or pain; Attention Regulation reports ability to control and sustain attention to sensations; Emotional Awareness reports awareness of links between bodily sensations and emotional affect; Self-Regulation reports how well an individual can self-regulate psychological distress by attending to body sensations; Body Listening reports ability to active listen for insights from the body; Trusting reports whether the body is experienced as a trustworthy and safe place. Thirty-seven Likert questions $(0,1,2,3,4,5)$ with $0=$ Never to left, $5=$ Always at the opposite. Temporal context was presented with the statement "Please reflect on how they apply to you generally in daily life." Cronbach's alpha testing covering all subscales found $\alpha=0.63$, Not Distracting and Not Worrying when removed increased alpha to $\alpha=0.79$, based on the standard collective minimum of $\alpha=0.70$ they were removed from the analysis (Tavakol \& Dennick, 2011).

The Body Appreciation Scale-2 (BAS-2; Appendix B), a revision, was adjusted to reduce sex specificity, and to remove dissatisfaction-based language (Tylka \& Wood-Barcalow, 2015). BAS-2 is unidimensional and contains 10 Likert questions $(1,2,3,4,5)$ with $1=$ Never, $5=$ Always at the opposite. Temporal context was presented with the statement "Indicate whether the question is true about you never, seldom, sometimes, often, or always."

The Eating Disorder Examination Questionnaire, version 6.0 (EDE-Q; Appendix C), a revision adapted to align with DSM-V (Fairburn, 2008). Four subscales measure: eating restraint and concern, and body shape and weight concern. Shape dimension 
covered degree of concern relating to preoccupation, dissatisfaction and importance of shape, flatness of stomach, fear of weight gain, discomfort seeing body, avoidance of exposure, and feelings of fatness. Weight covered degree of concern relating to importance of weight, reaction to prescribed weight, preoccupation with weight, dissatisfaction with weight and desire to lose weight. Thirteen Likert questions (No Days, 1-5 days, 6-12 days, 13-15 days, 16-22 days, 23-27 days, Every Day) for questions $6,8,10,11 \& 12$. And Likert $(0,1,2,3,4,5,6)$ with $01=$ Not at all at the left end of the spectrum and $6=$ Markedly, slightly and moderately equally spaced between the two. Temporal context was presented with the statement "Answer the questions considering the past four weeks (28 days)." Cronbach's alpha testing covering shape weight dimensions found $\alpha=0.97$, demonstrating an excellent level of consistency (Tavakol \& Dennick, 2011).

\section{Procedure}

Participants used a weblink to access the experiment. A simple, introduction outlined the experiment without reference to hypothesis or theory. Completion time given estimate 10 minutes. Ethical approval, consent, opt-out, data protection safeguards information was issued and acknowledged. Age, height, weight, gender (male, female, prefer not to say and prefer to self-describe) was collected. One sample question explained Likert scales. Participants were shown a brief explanation of the study. Each psychometric questionnaire was presented in MAIA-2, BAS-2 \& EDE-Q order. Upon completion to safeguard against distress contact details were given for BEAT, the UKs eating disorder charity, BDDF, the Body Dysmorphic Foundation, Samaritans and Mind for mental health support. A unique code was issued giving access to data should they request. 


\section{Results}

\section{Data Screening}

Analysis of questionnaire data revealed ordered response patterns assumed to be 'clicking through' (Stieger \& Reips, 2010), 8 naturist and 4 control participants were excluded.

\section{Descriptive Statistics}

Table 1 details mean and standard deviations for all experimental variables.

Bonferroni correction (BC; Bland \& Altman, 1995) was applied to the t-test results comparing means between groups with 12 variables $(p=.05 / 12=.004)$. Naturists mean age was significantly higher than controls, $t(73)=-7.31, p=<.001$ and their mean BMI was not significantly different, although higher, $\mathrm{t}(59)=-1.72, \mathrm{p}=0.09$.

Naturists without exception significantly achieved higher positive, and lower negative body image scores comparative to both internal and external results, this indicates lower symptomatology for ED.

BAS-2 means were higher than controls, $t(77)=-4.07, p=<.001$, indicating greater body image positivity. Clinical ED data for BAS-2 was not available for comparison but external study results (Table 2), show naturists scored significantly higher than British healthy male $\mathrm{t}(463)=5.74, \mathrm{p}=<.001$, and female groups $\mathrm{t}(487)=8.18, \mathrm{p}=<$ .001. Control population means were not significantly different from the British healthy male group $\mathrm{t}(456)=1.07, \mathrm{p}=0.29$. 
EDE-Q shape concern means were lower than controls, $t(77)=5.63, p=<.001$, indicating naturists were more comfortable with body shape. Clinical and healthy adult results (Table 3), were available for comparison, naturists scored significantly lower than Australian healthy females $\mathrm{t}(5296)=3.49, \mathrm{p}=<.001$, US clinical ED male patients $t(79)=7.19, p=<.001$, and Swedish clinical female patients $t(2366)=$ 16.66, $p=<.001$. Control means were significantly higher than Australian healthy females $t(5289)=2.07, p=0.04$, but significantly lower than both US clinical ED male patients $t(72)=2.40, p=0.02$, and Swedish clinical female patients $t(2359)=$ 8.66, $p=<.001$.

EDE-Q weight concern means were also lower than controls, $t(77)=5.11, p=<$ .001 , indicating naturists were more comfortable with their weight. Clinical and healthy adult scores (Table 4), were available for comparison, naturist scores were lower than Australian healthy females but the difference was not significant $t(5296)=$ 1.86, $p=0.06$, and they were significantly lower than both US clinical ED male patients $t(79)=6.42, p=<.001$, and Swedish clinical female patients $t(2366)=$ 12.72, $p=<.001$. Control means were significantly higher than Australian healthy females $\mathrm{t}(5289)=4.24, \mathrm{p}=<.001$, although lower than US clinical ED male patients $t(72)=1.61, p=0.11$ but the difference was not significant, and lower significantly than Swedish clinical female patients $\mathrm{t}(2359)=5.17, \mathrm{p}=<.001$.

MAIA-2 means for Trusting were significantly higher for naturists meaning they experienced their bodies as more safe and trustworthy, $\mathrm{t}(62)=-4.96, \mathrm{p}=<.001$, their mean Noticing scores were also significantly higher, they were more aware of comfortable, uncomfortable and neutral body sensations, $t(62)=-3.29, p=0.002$. Other MAIA-2 means were not significant after BC, but across all dimensions 
naturists demonstrated greater interoceptive ability than controls, only Attention Regulation was $p=>.05$. Body Listening means were higher, meaning they listened for insights more from the body, $t(71)=-2.05, p=0.04$. Emotional Awareness means were higher, indicating greater awareness of the connection between emotional states and emerging body sensations, $t(65)=-2.02, p=0.05$. Self-Regulation means were higher meaning their ability to regulate psychological distress through placing attention on sensations was greater, $\mathrm{t}(74)=-2.38, \mathrm{p}=0.02$. Attention Regulation means were higher meaning they were more able to control and sustain attention to bodily sensations, $\mathrm{t}(70)=-1.83, \mathrm{p}=0.07$.

\section{Correlation}

Table 1 details bivariate correlations for all experimental variables and both populations. BC (Bland \& Altman, 1995) was applied to the correlation results within groups covering 66 variables $(p=.05 / 66=.0008)$. Descriptions of correlation coefficients conform with guidance by Cohen (1992) as 0.5 high, 0.3 medium, and 0.1 low degree. Appendix D, Table D1 contains Fisher's Z transformation scores (Fisher, 1921) conducted to test the significance of the difference between correlation coefficients.

Controls BMI had a significant high degree of negative association with Trusting $r(34)=-.589, p=0.0002$, indicating that increasing weight reduced their experience of the body as a trustworthy and safe place, although not significant after BC, BMI also had a high degree of negative association with BAS-2, $r(34)=-.514, p=0.001)$, meaning weight gain also negatively affected their relationship with the body. Naturists BMI had a low degree of association and no significant correlations were 
found. Differences were significant between-group BMI and trusting correlations, $Z$ = 3.06, $\mathrm{p}=<.01$, and BMI and BAS-2, $\mathrm{Z}=2.26, \mathrm{p}=<.05$, meaning putting weight on did not lead to the same problems.

Both populations share the expected relationship direction between BAS-2 and shape and weight concern, being more body positive led to lower concern with shape and weight scores, associations were not significant for naturist shape $r(41)=$ $-.21, p=0.18$, and weight $r(41)=-.21, p=.18$, or control shape $r(34)=-.27, p=.11$ and weight $r(34)=-.15, p=.38$.

Naturist associations between BAS-2 and Trusting were significant after BC, positive and high degree, $r(41)=.60, p=0.00002$. Self-Regulation was significant to the default $p$ value threshold $(<.05), r(41)=.48, p=.001$, indicating increases in body appreciation led to experiencing the body as more trustworthy, and their ability to self-regulate psychological distress by attending to body sensations also improved. All other associations were low degree across Body Listening, Noticing, Attention Regulation and Emotional Awareness. Correlational differences were significant between group BAS-2 and Body Listening correlations, $Z=-3.00, p=<.01$, meaning improvements in body image led to a high degree of active listening for insights from the body from controls but not from naturists. Significant high degree positive associations between BAS-2 and MAIA-2 subscales existed for controls including Trusting $r(34)=.63, p=0.00004$; Body listening $r(34)=.58, p=0.0002$, and Attention Regulation $r(34)=.61, p=0.00008$. These relationships demonstrate that increasing body image positivity led to the body being experienced with greater trust, it improved their ability to both actively listen for insights and to control and sustain attention to sensations from the body. Self-Regulation, $r(34)=.39, p=0.02$, and 
Noticing, $r(34)=.37, p=0.02$, had positive medium degree associations significant to the default $p$ value threshold $(<.05)$, indicating controls also become more aware of bodily sensations and improved their ability to self-regulate psychological distress by attending to body sensations.

EDE-Q shape concern after BC highlighted no significant associations for naturists, at the default $p$ value threshold $(<.05)$, a medium degree association between shape concern and Emotional Awareness was found, $r(41)=.38, p=.01$, indicating that increasing shape concern led to greater awareness of the link between bodily sensations and emotional affect. For controls no significant associations were found after $\mathrm{BC}$, but at the default $p$ value threshold $(<.05)$, a medium degree relationship with Trusting was found $r(34)=-.39, p=.02$, meaning when they became more concerned about body shape they experienced their bodies as less safe and trustworthy. The differences between group shape concern and Trusting correlations was significant, $Z=2.193, p=<.05$, meaning naturists were not negatively affected in the same way.

EDE-Q weight concern was not significantly associated with any interoceptive subscales for the naturist or control population after $B C$, but at the default $p$ value threshold $(<.05)$, there was a medium degree association with Emotional Awareness for naturists, $r(41)=.46, p=.002$, meaning when they were concerned about weight they listened more to bodily sensations and were able to link them to emotional affect. 
Table 1

Bivariate Correlations, Means and Standard Deviations for Naturists (lower diagonal) and Controls (upper).

\begin{tabular}{|c|c|c|c|c|c|c|c|c|c|c|c|c|c|}
\hline & Variable & 1 & 2 & 3 & 4 & 5 & 6 & 7 & 8 & 9 & 10 & 11 & 12 \\
\hline 1. & Age & & $-0.53^{* *}$ & 0.16 & -0.04 & $-0.39^{*}$ & $-0.35^{\star}$ & -0.23 & -0.08 & 0.09 & -0.19 & 0.001 & 0.23 \\
\hline 2. & Gender & $-0.31^{*}$ & & 0.10 & -0.02 & $0.33^{*}$ & 0.29 & -0.08 & -0.04 & -0.23 & -0.05 & $-0.35^{*}$ & $-0.34^{*}$ \\
\hline 3. & BMI & 0.24 & -0.03 & & $-0.51^{* *}$ & 0.19 & 0.11 & -0.19 & -0.12 & -0.19 & 0.03 & -0.12 & -0.59 \\
\hline 4. & BAS-2 Body Appreciation & 0.09 & 0.007 & -0.04 & & -0.27 & -0.15 & 0.58 & $0.37^{*}$ & 0.61 & 0.19 & $0.39^{*}$ & 0.63 \\
\hline 5. & EDE-Q Shape Concern & -0.07 & -0.18 & 0.12 & -0.21 & & 0.94 & 0.11 & -0.08 & -0.13 & 0.13 & 0.03 & $-0.40^{\star}$ \\
\hline 6. & EDE-Q Weight Concern & -0.002 & -0.17 & 0.11 & -0.21 & 0.91 & & 0.28 & 0.07 & 0.01 & 0.15 & 0.11 & -0.32 \\
\hline 7. & MAIA-2 Body Listening & $-0.31^{*}$ & 0.13 & -0.14 & -0.04 & 0.12 & 0.22 & & $0.37^{*}$ & 0.63 & $0.37^{*}$ & $0.49^{* *}$ & 0.24 \\
\hline 8. & MAIA-2 Noticing & -0.04 & 0.06 & -0.003 & 0.06 & 0.16 & 0.17 & 0.20 & & $0.36^{*}$ & $0.44^{* *}$ & 0.23 & 0.08 \\
\hline 9. & MAIA-2 Attention Regulation & -0.09 & 0.18 & 0.22 & 0.26 & 0.18 & 0.21 & $0.32^{*}$ & $0.32^{*}$ & & 0.24 & 0.56 & $0.49^{* *}$ \\
\hline 10. & MAIA-2 Emotional Awareness & 0.13 & -0.29 & 0.23 & 0.08 & $0.38^{*}$ & $0.46^{* *}$ & 0.21 & $0.34^{*}$ & $0.42^{* *}$ & & $0.40^{*}$ & -0.03 \\
\hline 11. & MAIA-2 Self-Regulation & 0.09 & 0.23 & 0.09 & $0.48^{* *}$ & 0.10 & 0.12 & 0.24 & $0.31^{*}$ & 0.60 & 0.29 & & $0.46^{\star *}$ \\
\hline 12. & MAIA-2 Trusting & 0.21 & 0.13 & 0.04 & 0.60 & 0.09 & 0.10 & 0.02 & 0.23 & 0.53 & $0.32^{*}$ & $0.51^{* *}$ & \\
\hline M & (Naturist) & 57.47 & 1.07 & 27.68 & 4.15 & 1.35 & 1.36 & 3.16 & 3.72 & 3.29 & 3.66 & 3.56 & 4.29 \\
\hline SD & (Naturist) & 11.58 & 0.26 & 4.35 & 0.49 & 0.92 & 1.01 & 0.86 & 0.55 & 0.72 & 0.69 & 0.74 & 0.60 \\
\hline M & (Control) & 37.58 & 1.44 & 25.46 & 3.61 & 2.80 & 2.86 & 2.73 & 3.22 & 2.96 & 3.29 & 3.16 & 3.48 \\
\hline SD & (Control) & 12.40 & 0.50 & 6.61 & 0.70 & 1.35 & 1.57 & 0.98 & 0.76 & 0.83 & 0.89 & 0.74 & 0.84 \\
\hline $\begin{array}{l}t \\
p\end{array}$ & & $\begin{array}{c}-7.31 \\
<.001 \dagger\end{array}$ & $\begin{array}{c}4.26 \\
<.001 \dagger\end{array}$ & $\begin{array}{c}-1.72 \\
0.09\end{array}$ & $\begin{array}{c}-4.07 \\
<.001 \dagger\end{array}$ & $\begin{array}{c}5.63 \\
<.001 \dagger\end{array}$ & $\begin{array}{c}5.11 \\
<.001 \dagger\end{array}$ & $\begin{array}{l}-2.05 \\
0.04\end{array}$ & $\begin{array}{c}-3.29 \\
0.002 \dagger\end{array}$ & $\begin{array}{c}-1.83 \\
0.07\end{array}$ & $\begin{array}{c}-2.02 \\
0.05\end{array}$ & $\begin{array}{c}-2.38 \\
0.02\end{array}$ & $\begin{array}{c}-4.96 \\
<.001 \dagger\end{array}$ \\
\hline d & & 1.66 & 0.93 & 0.40 & 0.92 & -1.27 & -1.16 & 0.47 & 0.75 & 0.42 & 0.46 & 0.54 & 1.12 \\
\hline
\end{tabular}

a. Naturists $\mathrm{N}=43$, Controls $\mathrm{N}=36$.

b. ${ }^{*} p=<.05 ;{ }^{* *} p=<.01 ; \dagger=$ sig. after $B C(p=.05 / 12=.004)$; grey cells $=$ sig. after $B C(p=.05 / 66=.0008)$. 
Table 2

BAS-2 Body Appreciation Score Comparisons, Internal to Study and External Healthy Adults

\begin{tabular}{ccccccc}
\hline Population & Sex & $\begin{array}{c}\text { Age } \\
\text { range }\end{array}$ & $\begin{array}{c}\text { Age } \\
\text { M (SD) }\end{array}$ & N & $\begin{array}{c}\text { Score } \\
(\mathrm{SD})\end{array}$ & Source \\
\hline Naturist & Mixed & $26-74$ & 57.47 & 43 & 4.15 & Present Study \\
& & & $(11.58)$ & & $(0.49)$ & \\
Control & Mixed & $23-59$ & 37.58 & 36 & 3.61 & Present Study \\
& & & $(12.40)$ & & $(0.70)$ & \\
British & Male & $18-85$ & 39.13 & 422 & 3.47 & Alleva, Paraskeva, Craddock \& \\
healthy & & & $(13.76)$ & & $(0.76)$ & Diedrichs, 2018 \\
British & Female & \multirow{2}{*}{$18-76$} & 39.46 & 446 & 3.06 & Todd et al., 2019 \\
healthy & & & $(11.57)$ & & $(0.86)$ & \\
\hline
\end{tabular}

Table 3

EDE-Q Shape Concern Mean Score Comparisons, Internal to Study, Clinical ED Patients, and External Healthy Adults

\begin{tabular}{|c|c|c|c|c|c|c|}
\hline Population & Sex & $\begin{array}{l}\text { Age } \\
\text { range }\end{array}$ & $\begin{array}{l}\text { Age } \\
M(S D)\end{array}$ & $\mathrm{N}$ & $\begin{array}{l}\text { Score } \\
\text { (SD) }\end{array}$ & Source \\
\hline Naturist & Mixed & $26-74$ & $\begin{array}{c}57.47 \\
(11.58)\end{array}$ & 43 & $\begin{array}{c}1.35 \\
(0.92)\end{array}$ & Present Study \\
\hline $\begin{array}{l}\text { Australian } \\
\text { healthy }\end{array}$ & Female & $18-42$ & $\begin{array}{l}30.26 \\
(7.22)\end{array}$ & 5255 & $\begin{array}{c}2.23 \\
(1.65)\end{array}$ & $\begin{array}{c}\text { Mond, Hay, Rodgers \& Owen, } \\
2006\end{array}$ \\
\hline Control & Mixed & $23-59$ & $\begin{array}{c}37.58 \\
(12.40)\end{array}$ & 36 & $\begin{array}{c}2.80 \\
(1.35)\end{array}$ & Present Study \\
\hline US clinical & Male & $12-65$ & $\begin{array}{c}24.4 \\
(12.6)\end{array}$ & 38 & $\begin{array}{c}3.74 \\
(1.95)\end{array}$ & Jennings \& Phillips (2017) \\
\hline $\begin{array}{l}\text { Swedish } \\
\text { clinical }\end{array}$ & Female & $18-66$ & $\begin{array}{l}25.28 \\
(7.61)\end{array}$ & 2325 & $\begin{array}{c}4.72 \\
(1.32)\end{array}$ & $\begin{array}{c}\text { Welch, Birgegård, Parling \& } \\
\text { Ghaderi, } 2011\end{array}$ \\
\hline
\end{tabular}

Table 4

EDE-Q Weight Concern Mean Score Comparisons, Internal to Study, Clinical ED Patients, and External Healthy Adults

\begin{tabular}{|c|c|c|c|c|c|c|}
\hline $\begin{array}{c}\text { Populatio } \\
n\end{array}$ & Sex & $\begin{array}{l}\text { Age } \\
\text { range }\end{array}$ & $\begin{array}{l}\text { Age } \\
M(S D)\end{array}$ & $\mathrm{N}$ & $\begin{array}{l}\text { Score } \\
\text { (SD) }\end{array}$ & Source \\
\hline Naturist & Mixed & $26-74$ & $\begin{array}{c}57.47 \\
(11.58)\end{array}$ & 43 & $\begin{array}{c}1.36 \\
(1.01)\end{array}$ & Present Study \\
\hline $\begin{array}{l}\text { Australian } \\
\text { healthy }\end{array}$ & Female & $18-42$ & $\begin{array}{l}30.26 \\
(7.22)\end{array}$ & 5255 & $\begin{array}{c}1.79 \\
(1.51)\end{array}$ & $\begin{array}{c}\text { Mond, Hay, Rodgers \& Owen, } \\
2006\end{array}$ \\
\hline Control & Mixed & $23-59$ & $\begin{array}{c}37.58 \\
(12.40)\end{array}$ & 36 & $\begin{array}{c}2.86 \\
(1.57)\end{array}$ & Present Study \\
\hline $\begin{array}{l}\text { US } \\
\text { clinical }\end{array}$ & Male & $12-65$ & $\begin{array}{c}24.4 \\
(12.6)\end{array}$ & 38 & $\begin{array}{c}3.52 \\
(1.93)\end{array}$ & Jennings \& Phillips (2017) \\
\hline $\begin{array}{l}\text { Swedish } \\
\text { clinical }\end{array}$ & Female & $18-66$ & $\begin{array}{l}25.28 \\
(7.61)\end{array}$ & 2325 & $\begin{array}{c}4.07 \\
(1.39)\end{array}$ & $\begin{array}{c}\text { Welch, Birgegård, Parling \& } \\
\text { Ghaderi, } 2011\end{array}$ \\
\hline
\end{tabular}




\section{Discussion}

H1 was predicted correctly, naturists scored higher than controls and external reference studies that included large healthy adult samples on BAS-2, they also scored lower on EDE-Q shape and weight concern, again compared to both controls, healthy normative and clinical ED populations. Higher BAS-2 scores not only demonstrate greater body appreciation but also resilience against negative media influence, for EDE-Q lower scores indicate lower symptomatology for ED. Weight can be added to the generalizability of naturist results based on West (2018) prior findings. West's explanation for how naturist body appreciation might benefit from exposure to non-idealised bodies may be expanded upon based on Longo's (2017) residual deviation from the average body hypothesis whereby an individual's body image is based on a relative vector deviation from the average body. All theories align with the view that visibility of actual average rather than media representation average would lead to what may be explained as recalibration.

$\mathrm{H} 2$ was also predicted correctly, naturists scored significantly higher on the MAIA-2 Noticing subscale indicating they have greater ability to sense interoceptive signals. Theoretically this points to confirming that naturists neurologically do the opposite of ED patients, rather than downregulating interoceptive processing in favour of exteroceptive visual input as a defence they can rely on internal signals. The social psychological theories presented collectively offer an explanation as to why naturists would not feel the need to put up a defence, they would feel more comfortable having calibrated their body image. High degree MAIA-2 correlatory associations between BAS-2, Trusting and Self-Regulation subscales add weight to these assumptions based on their interpretation as experiencing the body as more 
trustworthy and possessing an improved ability to self-regulate psychological distress by attending to body sensations.

H3 prediction that relationships between BAS-2 and MAIA-2 subscales for both naturists and controls would be positive was correct, other than naturists Body Listening coefficient that was unexpectedly negative to a very low degree. Interestingly for naturists, although all means for MAIA-2 measures were higher at the univariate level, the strength of relationships here were lower than controls across all subscales other than Self-Regulation. After BC, only Trusting was significant for naturists, indicating they experienced their bodies as more trustworthy as BAS-2 increased. At the default $p$ value $(p=<.05)$, Self-Regulation was also significant and had a high positive degree association meaning they were better able to control and sustain attention to sensations.

For controls, after BC, relationships between BAS-2 and MAIA-2 were much stronger with Body Listening, Attention Regulation and Trusting achieving significance. Noticing and Self-Regulation were also significant to $p=<.05$, these relationships indicate that with increased body satisfaction controls were more aware of, and able to control sustained attention to sensations, they were able to self-regulate stress by listening to their bodies and it led to it feeling like a safer place. The unexpected difference between groups can potentially be explained because of the magnitude of the difference of effect for controls, potentially they had more headroom to improve.

H3 predicted MAIA-2 measures would negatively correlate with EDE-Q shape and weight for both naturists and controls but across both measures and groups only Trusting had a high degree negative association. There were no significant relationships after BC on any of the sub-scales but at the default $p$ value threshold ( $p$ 
$=<.05)$, Trusting became significant for controls indicating that as shape and weight concern became a problem their body didn't feel like a safe place. Although Trusting also had a high degree association for Naturists it was entirely insignificant, this may be partly explained by the higher resilience demonstrated at the univariate level through significantly higher Self-Regulation means. It was unexpected not to find more negative relationships, but the results are important because although not significant after BC, high degree positive associations with emotional awareness for both shape and weight indicate that when negative body image becomes a problem naturists are more resilient by listening to and linking bodily sensations with emotional affect rather than switching them off. This may be a transfer effect within the insular cortex as it is also a centre for emotional processing (Garfinkel et al., 2016), and it also aligns with the theory that positive and negative body image is not on a single continuum (Striegel-Moore \& Cachelin, 1999).

\section{Limitations}

$\mathrm{H} 2$ predicted naturists would be better at sensing signals from the body based on Tsakiris (2017) downregulation hypothesis, MAIA-2 has good convergent reliability (Bornemann, Herbert, Mehling \& Singer, 2015) but the self-reported Noticing subscale could be further validated using clinical interoceptive accuracy testing (Ainley \& Tsakiris, 2013). Neuroimaging could also be used to monitor insular cortex activity and exteroceptive occipital correlates (Sachdev et al., 2008).

Naturists were mainly male, and sex has been found to significantly influence body appreciation in some studies (Table 2; Tylka, 2013), although not all (Swami, HadjiMichael \& Furnham, 2008), their age was also significantly higher which can also vary body image results in men and women (Griffiths et al., 2016). West (2018) also 
found a large discrepancy in gender, reporting $12 \%$ and $19 \%$ female in two studies but in another purposely selecting 12 male and 12 females. Future studies should consider recruitment abroad where both sex and age are much more balanced (France, 2018a).

Correlatory analysis results provide an in-depth preliminary overview of the relationships between measures but it was not possible to infer causation as there was no measurement of effect over time, temporality implications are discussed further below.

Body parts carry negative affect for men and women leading to worsened health outcomes. Labiaplasty demand increased $45 \%$ in 2014/15 (ISAPS, 2017), psychological motives were embarrassment, anxiety and loss of self-esteem (Miklos \& Moore, 2008), age of enquiry is decreasing (Strickland, 2016). One-in-three British women avoid cervical screening because of embarrassment, body image and vulva dissatisfaction (NHS, 2018a). Penis ideals evolve historically, in Greco-Roman culture large male genitalia was considered ugly (Hardy, 2004). Today size is a problem for up to $45 \%$ of men, UK clinicians highlight 'small penis syndrome' concerning ability to satisfy along with abnormal privacy concerns (Wylie \& Eardley, 2007). The British NHS published a webpage to help (NHS, 2018b). Penis size averages are very similar (Jamison \& Gebhard, 1988) but paradoxically censorship introduces difficulty in communication of norms that could reduce dysmorphia. Breast augmentation is the top cosmetic surgery procedure (BAAPS, 2019). Psychological drivers were self-esteem, achieving ideal, appearance dissatisfaction and sexuality (Solvi et al., 2010), desire from adolescents has increased (Strickland, 2016). The UK has poor breast-feeding rates with $34 \%$ at six-months compared to $63 \%$ in 
Sweden (World Health Organisation, 2019). Sexualisation leads to stigma, judgement and harassment (Renfrew et al., 2016). Feeding can improve the immune system, intelligence, and digestive functions (Victora et al., 2016). Social nudity has been used as a way to promote better understanding of healthy norms such as genitalia focussed photography books that have been used in schools (Dodsworth, 2019). Given the high prevalence of body part shame and aversity to exposure future studies should consider the contribution relinquishment of shame and realisation of one's body parts as normal may have on body satisfaction scores. It may be possible to evolve or add to a clinical psychometric tool such as the Body Cathexis Scale (Secord \& Jourard, 1953).

\section{Philosophical Implications}

This study gives rise to philosophical questions about naturism that are likely to affect body image. Future consideration should be given to how positive selfaffirmatory suggestions following naturist activity transfer forwards. Internalisation of naturism as a construct of identity with body acceptance as a core belief over time may have a transfer effect that becomes a self-fulfilling prophecy based not only on social comparison, but also belief that the self holds more power over body image. Experimental testing for this effect may be devised by exploring differences between individuals who identify as naturists and those who attended and benefited from the experience of social nudity at a single event. Ideological subscription is difficult to measure but interesting research exists considering the impact of Protestantism on body satisfaction (Quinn \& Crocker (1999), higher residual beliefs negatively influenced well-being, and priming with protestant messages led to lower self-esteem compared to humanist stimulus. 
Other important philosophical considerations include assessment of the impact of cultural messages affecting norms, control and shame, described in sociological philosophy as techniques of the body (Mauss, 1935; Fuchs, 2017), these messages are ordained, largely instilled during childhood and beyond the grasp of consciousness (Bourdieu, 1977; Fuchs, 2017). Contrasting cultural messages can shed light on origins. Swedish parents encourage naked childhood activities to enhance body knowledge and confidence (McGurk, 2017, p.145), compared to the recent British strategy that also promotes improving knowledge but introduces privacy mantras (NSPCC, 2019). This is controversial for some parents with Neuroscientist Mayim Bialik specifically commenting on potential side effects (Bialik, 2016). Habitus is also a powerful concept that may help deconstruct cultural differences relating to body shame, defined as aspects of culture rooted in the body and it's daily practice (Mauss, 1935; Fuchs, 2017), covering bodily social appearance in its entirety including manners, clothing, posture and ways of life relative to social class (Bourdieu, 1990; Fuchs, 2017).

Naturists are a unique population culturally and future investigations should try to deconstruct differences relating to these philosophical points, the practice may for example be viewed as partly transcending class because of appearance uniformity, phenomenological investigations could be employed, and this approach would align with world ED experts vision to dig deeper into positive body image (Smolak \& Cash, 2011). 


\section{The Temporal Effect of Naturism on Body Image}

Alongside breaking down naturism phenomenologically, greater understanding of the temporal effect of social nudity on body image is needed to move forward towards an applied psychological solution. Research is currently limited to three studies specifically considering temporality, (Table 5).

\section{Table 5}

Effects of Social Nudity Over Time on Body Satisfaction

\begin{tabular}{clcccccc}
\hline Study & Population & Sex & $\begin{array}{c}\text { Age } \\
\text { M (SD) }\end{array}$ & N & $\begin{array}{c}\text { Exposure } \\
(\mathrm{min})\end{array}$ & $\begin{array}{c}\text { Before } \\
\text { Score (SD) }\end{array}$ & $\begin{array}{c}\text { After } \\
\text { Score (SD) }\end{array}$ \\
\hline 1 & Naked & Mixed & $\begin{array}{c}22 \\
\text { charity walk }\end{array}$ & 24 & 90 & $3.00(1.02)$ & $3.29(0.91)$ \\
& Naked & Mixed & $\begin{array}{c}(14.47) \\
45.36\end{array}$ & 100 & 180 & $3.32(0.93)$ & $3.55(0.85)$ \\
& $\begin{array}{l}\text { Naterpark } \\
3\end{array}$ & $\begin{array}{c}(13.92) \\
\text { Life }\end{array}$ & $\begin{array}{c}\text { Femal } \\
20.19\end{array}$ & 37 & 240 & $4.24(1.74)$ & $5.32(1.87)$ \\
& drawing & $\mathrm{e}$ & $(3.00)$ & & & & \\
\hline
\end{tabular}

Note:

a) Authors: studies 1-2, West (2018), study 3, Swami (2016).

b) Body image instruments: studies 1-2, Body Appreciation Scale 1 (Avalos, Tylka \& Wood-Barcalow, 2005); study 3. Body Image States Scale (Cash, Fleming, Alindogan, Steadman \& Whitehead, 2002).

Main factors of interest to consider include; Body image measurement time series values: As with West (2018) and Swami (2016), a minimum requirement; Prior experience of naturism: West created an index variable of naturist experience combining the product of years and frequency as part of a separate cross-sectional study, he found a significant relationship with body satisfaction; Subscription to naturist philosophy: with reference to the implications above, the level of knowledge, and internalisation of naturist values alongside experience is important and connected but separate from experience alone, development of a questionnaire is recommended; Length of activity: West's events were single and ranged between 90 and 180 minutes, Swami's events were uniform, and the total time involved two events on separate occasions. A standardised approach would be beneficial, 
breaking out multiple events and considering retention; Demographic of naked community: Swami found just one naked individual influenced appreciation, more work to consider how dynamic this variable is and variance between individuals; Retention: Swami reported retention following an unspecified break within a month period, further consideration should be given to maintenance, ultimately as with fitness activities a practitioner may in future help a client calculate individual requirement to maintain body image; Influences upon retention: borrowing assumptions from the tripartite influence model of body image and eating disturbance (Thompson, Coovert \& Stormer, 1999), exposure to media, and communications with parents and peers can be analysed in between events; Decay: considering both retention and activities that increase or decrease body positivity, within a longer-term holiday study, to consider decay of body satisfaction within a controlled environment post measurement, for example before going to bed and the following morning halfway through a holiday; Standardisation of instruments: prior investigations did not employ the same measures, a collaborative standardised approach would benefit in future; Sustainability: Life drawing, compared to sauna for example, although dependent upon local facilities may be more popular over months or years and have more universal appeal.

Participant selection is also crucially linked to the above points covering temporality. Bray (2019) hosted a reality television show, Naked Beach, in conjunction with Dr. Keon West that helped individuals suffering from body image concerns by spending time in a similar environment to a naturist holiday. The outcomes were positive from both participant and public, but it was not reported as an experiment. This should be replicated in future at one of the European naturist centres. 
Finally, a longitudinal study should be planned, ideally in conjunction with a university in West France with a local large naturist resort where $70-80 \%$ of customers are families (France, 2018a), and many people own properties and return every year, many for their entire life since birth, this can help answer the questions about whether naturist children are more resilient to ED over 15 to 20 years.

\section{Conclusion}

This study successfully part replicated work by West (2018) that first established the link between naturism and positive body image. It went further by introducing a negative body image instrument commonly used to assess eating disorder treatment efficacy. All body image instrument results for Naturists agreed with the hypothesis that as a population they are highly resilient to negative body image when compared both to controls within study and external clinical and healthy normative data. West's posits on theory were built upon, adding social psychological and cognitive theories about how naturism may help people recalibrate body image based on the residual deviation from average hypothesis (Longo, 2017). Alongside body image, the study also made a preliminary assessment of naturist interoceptive awareness, the population scored consistently higher than controls across every measure with significant results after Bonferroni correction across four of six subscales, others were significant to $p=0.05$ and 0.07 . Inferences were made about the neurological basis and benefits Naturism may provide that appear to be the reverse of those found in patients suffering with ED as outlined in Tsakiris et al., (2018) interoceptive downregulation hypothesis. 
Many relevant and connected recommendations were made including suggestions for adaptation and employment of a body cathexis scale to include genitalia. The philosophical and sociological implications that may influence naturist body image related self-fulfilling prophecies were discussed that will ideally lead to in depth phenomenological inquiry. Options for future temporal and longitudinal studies were made including clinical and neuroimaging studies.

Body image has become an epidemic in the Western world and many people feel under extreme pressure to conform to the slender ideal. Regulation of the body in advertising and media is not a viable option due to global regulatory differences and the negative effect of skinny and athlete shaming that would result from enforced choice of oversize models. Potentially naturism can be employed as a proactive mind-body therapy to help improve body image concerns and act as an antidote to low body satisfaction. Naturism is a universal and already well-established holistic solution (Visit Finland, 2020; France, 2018b). Despite historical negativity towards the practice the British public are becoming more interested as the media opens up to lower censorship helping people to easier differentiate between sexual and nonsexual nudity. Public views can change radically over time, a good example is written in the obituary of Christiane Lecocq, Founder of CHM Montalivet (Telegraph, 2015), saying "grew up at a time when women were beginning to expose their ankles and arms". 


\section{References}

Ainley, V., \& Tsakiris, M. (2013). Body conscious? Interoceptive awareness, measured by heartbeat perception, is negatively correlated with selfobjectification. PloS one, 8(2).

https://doi.org/10.1371/journal.pone.0055568

Alleva, J.M., Paraskeva, N., Craddock, N., \& Diedrichs, P.C. (2018). Body appreciation in British men: Correlates and variation across sexual orientation. Body Image, 27, 169-178.

https://doi.org/10.1016/j.bodyim.2018.09.004

Almeida, A., Correia, I., \& Marinho, S. (2009). Moral disengagement, normative beliefs of peer group, and attitudes regarding roles in bullying. Journal of School Violence, 9(1), 23-36.

https://doi.org/10.1080/15388220903185639

Avalos, L., Tylka, T. L., \& Wood-Barcalow, N. (2005). The body appreciation scale: Development and psychometric evaluation. Body Image, 2(3), 285-297 https://doi.org/10.1016/i.bodyim.2005.06.002

BAAPS. (2019, 20 May). Cosmetic surgery stats: number of surgeries remains stable amid calls for greater regulation of quick fix solutions. Retrieved from https://baaps.org.uk/about/news/1708/cosmetic_surgery_stats_number_of_surgeries _remains_stable_amid_calls_for_greater_regulation_of_quick_fix_solutions 
Bandura, A., Ross, D., \& Ross, S. A. (1961). Transmission of aggression through imitation of aggressive models. The Journal of Abnormal and Social Psychology, 63(3), 575.

https://doi.org/10.1037/h0045925

Bandura, A. (1962). Social learning through imitation. In M. R. Jones (Ed.), Nebraska Symposium on Motivation, 1962 (p. 211-274). University of Nebraska Press.

Barlett, C. P., Vowels, C. L., \& Saucier, D. A. (2008). Meta-analyses of the effects of media images on men's body-image concerns. Journal of social and clinical psychology, 27(3), 279-310.

https://doi.org/10.1521/jscp.2008.27.3.279

Becker, A. E. (2004). Television, disordered eating, and young women in Fiji: Negotiating body image and identity during rapid social change. Culture, medicine and psychiatry, 28(4), 533-559.

https://doi.org/10.1007/s11013-004-1067-5

Berlucchi, G., \& Aglioti, S. M. (2010). The body in the brain revisited. Experimental brain research, 200(1), 25.

https://doi.org/10.1007/s00221-009-1970-7

Bialik, M. (2016, 14 July). The Naked Truth: It's Nude Day, My attitude about nudity from a parenting perspective [Blog Post]. Retrieved from 
https://groknation.com/relating/nude-day/

Bland, J. M., \& Altman, D. G. (1995). Multiple significance tests: the Bonferroni method. Bmj, 310(6973), 170.

https://doi.org/10.1136/bmi.310.6973.170

Boothroyd, L. G., Jucker, J. L., Thornborrow, T., Jamieson, M. A., Burt, D. M., Barton, R. A., ... \& Tovee, M. J. (2016). Television exposure predicts body size ideals in rural Nicaragua. British Journal of Psychology, 107(4), 752-767. https://doi.org/10.1111/bjop.12184

Bordo, S. (2004). Unbearable weight: Feminism, Western culture, and the body. University of California Press.

Bornemann, B., Herbert, B. M., Mehling, W. E., \& Singer, T. (2015). Differential changes in self-reported aspects of interoceptive awareness through 3 months of contemplative training. Frontiers in psychology, 5, 1504.

https://doi.org/10.3389/fpsyg.2014.01504

Bourdieu, P. (1977). Outline of a Theory of Practice (Vol. 16). Cambridge university press.

Bourdieu, P. (1990). The logic of practice. Stanford university press. 
Boynton, P. M., \& Greenhalgh, T. (2004). Selecting, designing, and developing your questionnaire. Bmj, 328(7451), 1312-1315.

https://doi.org/10.1136/bmj.328.7451.1312

Bray, R. (2019). Naked Beach. Channel 4. London, UK: Bareface TV https://www.broadcastnow.co.uk/broadcasters/naked-beach-channel4/5138480.article

British Naturism. (2019). What is Naturism. Retrieved from https://www.bn.org.uk/aboutnaturism/

Brewer, R., Cook, R., \& Bird, G. (2016). Alexithymia: a general deficit of interoception. Royal Society open science, 3(10), 150664.

https://doi.org/10.1098/rsos.150664

Cash, T.F., Fleming, E.C., Alindogan, J., Steadman, L., Whitehead, A., 2002. Beyond body image as a trait: the development and validation of the Body Image States Scale. Eating Disorders, 10, 103-113.

https://doi.org/10.1080/10640260290081678

Clark, L., \& Tiggemann, M. (2007). Sociocultural influences and body image in 9 to 12-year-old girls: The role of appearance schemas. Journal of Clinical Child and Adolescent Psychology, 36(1), 76-86.

https://doi.org/10.1080/15374410709336570 
Cohen, J. (1992). A power primer. Psychological bulletin, 112(1), 155.

https://doi.org/10.1037/0033-2909.112.1.155

Craig, A. D. (2004). Human feelings: why are some more aware than others? Trends in cognitive sciences, 8(6), 239-241.

https://doi.org/10.1016/j.tics.2004.04.004

Culbert, K. M., Racine, S. E., \& Klump, K. L. (2015). Research Review: What we have learned about the causes of eating disorders - a synthesis of sociocultural, psychological, and biological research. Journal of Child Psychology and Psychiatry, 56(11), 1141-1164.

https://doi.org/10.1111/jcpp.12441

Daubenmier, J. J. (2005). The relationship of yoga, body awareness, and body responsiveness to self-objectification and disordered eating. Psychology of Women Quarterly, 29(2), 207-219.

https://doi.org/10.1111/j.1471-6402.2005.00183.x

Dodsworth, L. (2019). Womanhood: The Bare Reality (1st ed.). London, UK: Pinter \& Martin

https://www.lauradodsworth.com/bare-reality

European Parliament. (2018). Regulation (EU) 2016/679 GDPR. Official Journal of the European Union (OJ), 59(1-88), 294.

https://gdpr-info.eu 
Fairburn, C. G. (2008). Cognitive behaviour therapy and eating disorders. Guilford Press.

Fairburn, C. G., \& Beglin, S. J. (1994). Assessment of eating disorders: Interview or self-report questionnaire? International journal of eating disorders, 16(4), 363-370. https://onlinelibrary.wiley.com/doi/abs/10.1002/1098108X(199412)16:4\%3C363::AID-EAT2260160405\%3E3.0.CO;2-\%23

Farb, N. A., Segal, Z. V., \& Anderson, A. K. (2013). Mindfulness meditation training alters cortical representations of interoceptive attention. Social cognitive and affective neuroscience, 8(1), 15-26.

https://doi.org/10.1093/scan/nss066

Fallon, E. A., Harris, B. S., \& Johnson, P. (2014). Prevalence of body dissatisfaction among a United States adult sample. Eating behaviors, 15(1), 151-158. https://doi.org/10.1016/i.eatbeh.2013.11.007

Fisher, R. A. (1921). 014: On the" Probable Error" of a Coefficient of Correlation Deduced from a Small Sample. https://hekyll.services.adelaide.edu.au/dspace/bitstream/2440/15169/1/14.pdf France. (2018a). FAQ for Naturism in France. Retrieved from https://uk.france.fr/en/news/article/faq-naturism-france 
France. (2018b). Naturist places in France. Retrieved from

https://uk.france.fr/en/news/article/naturist-places-france

Fuchs, T. (2017). 17 Collective Body Memories. Embodiment, enaction, and culture: investigating the constitution of the shared world, London, UK: MIT Press

Furnham, A., \& Alibhai, N. (1983). Cross-cultural differences in the perception of female body shapes. Psychological medicine, 13(4), 829-837

https://doi.org/10.1017/S0033291700051540

Furnham, A., \& Greaves, N. (1994). Gender and locus of control correlates of body image dissatisfaction. European Journal of Personality, 8(3), 183-200.

https://doi.org/10.1002/per.2410080304

Gaete, M. I., \& Fuchs, T. (2016). From body image to emotional bodily experience in eating disorders. Journal of Phenomenological Psychology, 47(1), 17-40. https://doi.org/10.1163/15691624-12341303

Galmiche, M., Déchelotte, P., Lambert, G., \& Tavolacci, M. P. (2019). Prevalence of eating disorders over the 2000-2018 period: a systematic literature review. The American journal of clinical nutrition, 109(5), 1402-1413.

https://doi.org/10.1093/ajen/nqy342

Garfinkel, S. N., Manassei, M. F., Hamilton-Fletcher, G., In den Bosch, Y., Critchley, H. D., \& Engels, M. (2016). Interoceptive dimensions across cardiac and respiratory 
axes. Philosophical Transactions of the Royal Society B: Biological

Sciences, 371(1708), 20160014.

https://doi.org/10.1098/rstb.2016.0014

Garfinkel, S. N., Tiley, C., O'Keeffe, S., Harrison, N. A., Seth, A. K., \& Critchley, H.

D. (2016). Discrepancies between dimensions of interoception in autism:

Implications for emotion and anxiety. Biological psychology, 114, 117-126.

https://doi.org/10.1016/i.biopsycho.2015.12.003

Gaudio, S., \& Quattrocchi, C. C. (2012). Neural basis of a multidimensional model of body image distortion in anorexia nervosa. Neuroscience \& Biobehavioral Reviews, 36(8), 1839-1847.

https://doi.org/10.1016/i.neubiorev.2012.05.003

Green, L. (2001). Hiding behind nakedness on the nude beach [An earlier version of this paper was presented at On the Beach: Cultural Studies Association of Australia Conference (2000: Brisbane).]. Australian Journal of Communication, 28(3), 1. http://ro.ecu.edu.au/cgi/viewcontent.cgi?article=5454\&context=ecuworks

Griffiths, S., Hay, P., Mitchison, D., Mond, J. M., McLean, S. A., Rodgers, B., ... \& Paxton, S. J. (2016). Sex differences in the relationships between body dissatisfaction, quality of life and psychological distress. Australian and New Zealand Journal of Public Health, 40(6), 518-522.

https://doi.org/10.1111/1753-6405.12538 
Groesz, L. M., Levine, M. P., \& Murnen, S. K. (2002). The effect of experimental presentation of thin media images on body satisfaction: A meta-analytic review. International Journal of eating disorders, 31(1), 1-16.

https://doi.org/10.1002/eat.10005

Haggard, P., lannetti, G. D., \& Longo, M. R. (2013). Spatial sensory organization and body representation in pain perception. Current Biology, 23(4), R164-R176. https://doi.org/10.1016/j.cub.2013.01.047

Halmi, K. A. (2013). Perplexities of treatment resistance in eating disorders. BMC psychiatry, 13(1), 292.

https://doi.org/10.1186/1471-244X-13-292

Hanley, A. W., Mehling, W. E., \& Garland, E. L. (2017). Holding the body in mind: Interoceptive awareness, dispositional mindfulness and psychological wellbeing. Journal of psychosomatic research, 99, 13-20.

https://doi.org/10.1016/j.jpsychores.2017.05.014

Hardy, S. (2004). The Greeks, eroticism and ourselves. Sexualities, 7(2), 201-216. https://doi.org/10.1177/1363460704042164

Harris, J. R. (1995). Where is the child's environment? A group socialization theory of development. Psychological review, 102(3), 458.

https://doi.org/10.1037/0033-295X.102.3.458 
Herbert, B. M., Muth, E. R., Pollatos, O., \& Herbert, C. (2012). Interoception across modalities: on the relationship between cardiac awareness and the sensitivity for gastric functions. PloS one, 7(5), e36646.

https://doi.org/10.1371/journal.pone.0036646

Herbert, B. M., \& Pollatos, O. (2014). Attenuated interoceptive sensitivity in overweight and obese individuals. Eating behaviours, 15(3), 445-448.

https://doi.org/10.1016/i.eatbeh.2014.06.002

Herbozo, S., \& Thompson, J. K. (2006). Appearance-related commentary, body image, and self-esteem: Does the distress associated with the commentary matter? Body image, 3(3), 255-262.

https://doi.org/10.1016/i.bodyim.2006.04.001

Higgins, E. T. (1987). Self-discrepancy: a theory relating self and affect. Psychological review, 94(3), 319. https://pdfs.semanticscholar.org/a59e/1e54374a90b854e0d1d443168325a26bef48.p df

International Naturist Federation. (n.d.). History of Naturism [Fact sheet]. https://downloads.inf-fni.org/download/65/english/452/focus-february-2020.pdf

ISAPS. (2017, 5 August). Plastic Surgeries Trends on the Rise. Retrieved from https://www.isaps.org/blog/plastic-surgeries-trends-rise/ 
Jamison, P. L., \& Gebhard, P. H. (1988). Penis size increase between flaccid and erect states: an analysis of the Kinsey data. Journal of sex research, 24(1), 177-183. https://doi.org/10.1080/00224498809551408

Jennings, K. M., \& Phillips, K. E. (2017). Eating Disorder Examination-Questionnaire (EDE-Q): Norms for a clinical sample of males. Archives of Psychiatric Nursing, 31(1), 73-76.

https://doi.org/10.1016/i.apnu.2016.08.004

Khalsa, S. S., Adolphs, R., Cameron, O. G., Critchley, H. D., Davenport, P. W., Feinstein, J. S., ... \& Meuret, A. E. (2018). Interoception and mental health: a roadmap. Biological Psychiatry: Cognitive Neuroscience and Neuroimaging, 3(6), 501-513.

https://doi.org/10.1016/j.bpsc.2017.12.004

Khalsa, S. S., \& Lapidus, R. C. (2016). Can interoception improve the pragmatic search for biomarkers in psychiatry? Frontiers in psychiatry, 7, 121. https://doi.org/10.3389/fpsyt.2016.00121

Kim, H., \& Damhorst, M. L. (2010). The relationship of body-related self-discrepancy to body dissatisfaction, apparel involvement, concerns with fit and size of garments, and purchase intentions in online apparel shopping. Clothing and Textiles Research Journal, 28(4), 239-254.

https://doi.org/10.1177/0887302X10379266 
Klaczynski, P. A., Goold, K. W., \& Mudry, J. J. (2004). Culture, obesity stereotypes, self-esteem, and the "thin ideal": A social identity perspective. Journal of youth and adolescence, 33(4), 307-317.

https://doi.org/10.1023/B:JOYO.0000032639.71472.19

Kurth, F., Zilles, K., Fox, P. T., Laird, A. R., \& Eickhoff, S. B. (2010). A link between the systems: functional differentiation and integration within the human insula revealed by meta-analysis. Brain Structure and Function, 214(5-6), 519-534 https://doi.org/10.1007/s00429-010-0255-z

Levine, J. M., Resnick, L. B., \& Higgins, E. T. (1993). Social foundations of cognition. Annual review of psychology, 44(1), 585-612.

https://www.annualreviews.org/doi/pdf/10.1146/annurev.ps.44.020193.003101

Levy, D. M. (1932). Body interest in children and hypochondriasis. American Journal of Psychiatry, 89(2), 295-315.

https://doi.org/10.1176/ajp.89.2.295

Longo, M. R. (2017). Body representations and the sense of self. The subject's matter: Self-consciousness and the body, 75-96. In: de Vignemont, F., \& Alsmith, A. J. (Eds.). (2017). The Subject's Matter: Self-Consciousness and the Body. MIT Press.

Mauss, M. (1973). Techniques of the Body. Economy and society, 2(1), 70-88. http://www.waffler.org/wp-content/uploads/2009/05/techniques-of-the-body.pdf 
McGurk, L. Å. (2017). There's No Such Thing as Bad Weather: A Scandinavian Mom's Secrets for Raising Healthy, Resilient, and Confident Kids (from Friluftsliv to Hygge). Simon and Schuster.

McLaren, L. (2007). Socioeconomic status and obesity. Epidemiologic reviews, 29(1), 29-48.

https://doi.org/10.1093/epirev/mxm001

Mehling, W. E., Acree, M., Stewart, A., Silas, J., \& Jones, A. (2018). The Multidimensional Assessment of Interoceptive Awareness, Version 2 (MAIA-2). PloS one, 13(12), e0208034.

https://doi.org/10.1371/journal.pone.0208034

Mehling, W. E., Price, C., Daubenmier, J. J., Acree, M., Bartmess, E., \& Stewart, A. (2012). The Multidimensional Assessment of Interoceptive Awareness (MAIA). PloS one, 7(11), Article e48230.

https://doi.org/10.1371/journal.pone.0048230

Mehling, W. E., Price, C. J., Daubenmier, J., Mike, A., Bartmess, E., \& Stewart, A. (2014). Body awareness and the practice of yoga or meditation in 435 primary care patients with past or current low back pain. The Journal of Alternative and Complementary Medicine, 20(5), A63-A64.

https://doi.org/10.1089/acm.2014.5165.abstract 
Miklos, J. R., \& Moore, R. D. (2008). Labiaplasty of the labia minora: patients' indications for pursuing surgery. The journal of sexual medicine, 5(6), 1492-1495. https://doi.org/10.1111/j.1743-6109.2008.00813.x

Mond, J. M., Hay, P. J., Rodgers, B., \& Owen, C. (2006). Eating Disorder Examination Questionnaire (EDE-Q): norms for young adult women. Behaviour research and therapy, 44(1), 53-62.

https://doi.org/10.1016/i.brat.2004.12.003

NHS. (2018a, 22 January). One in three women don't attend cervical screening because of 'embarrassment'. Retrieved from

https://www.nhs.uk/news/cancer/one-three-women-dont-attend-cervical-screeningbecause-embarrassment/

NHS. (2018b, 6 April). Penis size: Sexual health. Retrieved from https://www.nhs.uk/live-well/sexual-health/penis-size/

NHS. (2019, 15 July). What is the Body Mass Index? Retrieved from https://www.nhs.uk/common-health-questions/lifestyle/what-is-the-body-mass-index$\mathrm{bmi} /$

NSPCC. (2019). PANTS: The Underwear Rule. Retrieved from https://www.nspcc.org.uk/keeping-children-safe/support-for-parents/underwear-rule/ 
Okami, P., Olmstead, R., Abramson, P. R., \& Pendleton, L. (1998). Early childhood exposure to parental nudity and scenes of parental sexuality ("primal scenes"): An 18-year longitudinal study of outcome. Archives of Sexual Behaviour, 27(4), 361-384 https://doi.org/10.1023/A:1018736109563

Paulus, M. P., \& Stein, M. B. (2010). Interoception in anxiety and depression. Brain structure and Function, 214(5-6), 451-463.

https://doi.org/10.1007/s00429-010-0258-9

Puhl, R., Peterson, J. L., \& Luedicke, J. (2013). Fighting obesity or obese persons? Public perceptions of obesity-related health messages. International Journal of Obesity, 37(6), 774-782.

https://doi.org/10.1038/ijo.2012.156

Quinn, D. M., \& Crocker, J. (1999). When ideology hurts: effects of belief in the protestant ethic and feeling overweight on the psychological well-being of women. Journal of personality and social psychology, 77(2), 402. https://doi.org/10.1037/0022-3514.77.2.402

Re, D. E., Coetzee, V., Xiao, D., Buls, D., Tiddeman, B. P., Boothroyd, L. G., \& Perrett, D. I. (2011). Viewing heavy bodies enhances preferences for facial adiposity. Journal of Evolutionary Psychology, 9(4), 295-308.

https://doi.org/10.1556/JEP.9.2011.4.2 
Renfrew, M. J., Pokhrel, S., Quigley, M., McCormick, F., Fox-Rushby, J., Dodds, R., ... \& Williams, A. (2012). Preventing disease and saving resources: the potential contribution of increasing breastfeeding rates in the UK. UNICEF. http://bura.brunel.ac.uk/handle/2438/10266

Sachdev, P., Mondraty, N., Wen, W., \& Gulliford, K. (2008). Brains of anorexia nervosa patients process self-images differently from non-self-images: an fMRI study. Neuropsychologia, 46(8), 2161-2168.

https://doi.org/10.1016/j.neuropsychologia.2008.02.031

Secord, P. F., \& Jourard, S. M. (1953). The appraisal of body-cathexis: bodycathexis and the self. Journal of consulting psychology, 17(5), 343. https://doi.org/10.1037/h0060689

Seid RP (1994). Too 'close to the bone': the historical context for women's obsession with slenderness. In: Fallon P, Katzman MA, Wooley SC (eds). Feminist Perspectives on Eating Disorders. The Guildford Press: London. pp. 3-17.

Singer, T., Critchley, H. D., \& Preuschoff, K. (2009). A common role of insula in feelings, empathy and uncertainty. Trends in cognitive sciences, 13(8), 334-340. https://doi.org/10.1016/j.tics.2009.05.001

Skårderud, F. (2009). Bruch revisited and revised. European Eating Disorders Review: The Professional Journal of the Eating Disorders Association, 17(2), 83-88. https://doi.org/10.1002/erv.923 
Smolak, L., \& Cash, T. F. (2011). Future challenges for body image science, practice, and prevention. Guilford Press.

Solvi, A. S., Foss, K., von Soest, T., Roald, H. E., Skolleborg, K. C., \& Holte, A. (2010). Motivational factors and psychological processes in cosmetic breast augmentation surgery. Journal of Plastic, Reconstructive \& Aesthetic Surgery, 63(4), 673-680.

https://doi.org/10.1016/j.bjps.2009.01.024

Story, M. D. (1979). Factors associated with more positive body self-concepts in preschool children. The Journal of social psychology, 108(1), 49-56.

https://doi.org/10.1080/00224545.1979.9711960

Story, M. (1984). Comparisons of body self-concept between social nudists and nonnudists. The Journal of psychology, 118(1), 99-112.

https://doi.org/10.1080/00223980.1984.9712599

Stieger, S., \& Reips, U. D. (2010). What are participants doing while filling in an online questionnaire: A paradata collection tool and an empirical study. Computers in Human Behavior, 26(6), 1488-1495.

https://doi.org/10.1016/j.chb.2010.05.013

Strickland, J. L. (2016). Breast and Labial Surgery in Adolescents. Obstetrics and Gynecology, 127(5), E138-E140. 
https://obgin.net/wp-content/uploads/2018/07/Committee-Opinion-No-662.-Breastand-Labial-Surgery-in-Adolescents.pdf

Striegel-Moore, R. H., \& Cachelin, F. M. (1999). Body image concerns and disordered eating in adolescent girls: Risk and protective factors. In N. G. Johnson, M. C. Roberts, \& J. Worell (Eds.), Beyond appearance: A new look at adolescent girls (p. 85-108). American Psychological Association.

https://doi.org/10.1037/10325-003

Suls, J., \& Wheeler, L. (Eds.). (2013). Handbook of social comparison: Theory and research. Springer Science \& Business Media.

Swami, V. (2016). Illustrating the body: Cross-sectional and prospective investigations of the impact of life drawing sessions on body image. Psychiatry research, 235, 128-132.

https://doi.org/10.1016/j.psychres.2015.11.034

Swami, V., Hadji-Michael, M., \& Furnham, A. (2008). Personality and individual difference correlates of positive body image. Body image, 5(3), 322-325. https://doi.org/10.1016/j.bodyim.2008.03.007

Sze, J. A., Gyurak, A., Yuan, J. W., \& Levenson, R. W. (2010). Coherence between emotional experience and physiology: does body awareness training have an impact? Emotion, 10(6), 803.

https://doi.org/10.1037/a0020146 
Tavakol, M., \& Dennick, R. (2011). Making sense of Cronbach's alpha. International journal of medical education, 2, 53.

https://doi.org/10.5116/ijme.4dfb.8dfd

Telegraph. (2015, 16 January). Christiane Lecocq, Naturist, Obituary. Retrieved from https://www.telegraph.co.uk/news/obituaries/11350720/Christiane-Lecocq-naturistobituary.html

Thompson, J. K., Coovert, M. D., \& Stormer, S. M. (1999). Body image, social comparison, and eating disturbance: A covariance structure modelling investigation. International Journal of Eating Disorders, 26(1), 43-51. https://doi.org/10.1002/(SICI)1098-108X(199907)26:1<43::AID-EAT6>3.0.CO;2-R

Thornton, L. M., Mazzeo, S. E., \& Bulik, C. M. (2010). The heritability of eating disorders: methods and current findings. Behavioural neurobiology of eating disorders (pp. 141-156). Springer, Berlin, Heidelberg. https://doi.org/10.1007/7854_2010_91

Tiggemann, M., \& Slater, A. (2014). NetTweens: The internet and body image concerns in preteenage girls. The Journal of Early Adolescence, 34(5), 606-620. https://doi.org/10.1177/0272431613501083 
Todd, J., Aspell, J. E., Barron, D., \& Swami, V. (2019). Multiple dimensions of interoceptive awareness are associated with facets of body image in British adults. Body image, 29, 6-16.

https://doi.org/10.1016/j.bodyim.2019.02.003

Tsakiris, M. (2017). The multisensory basis of the self: from body to identity to others. The Quarterly Journal of Experimental Psychology, 70(4), 597-609. https://doi.org/10.1080/17470218.2016.1181768

Tsakiris, M., \& De Preester, H. (Eds.). (2018). The interoceptive mind: from homeostasis to awareness. Oxford University Press.

Tylka, T. L. (2013). Evidence for the Body Appreciation Scale's measurement equivalence/invariance between US college women and men. Body Image, 10(3), 415-418.

https://doi.org/10.1016/j.bodyim.2013.02.006

Tylka, T. L., \& Wood-Barcalow, N. L. (2015). The Body Appreciation Scale-2: item refinement and psychometric evaluation. Body image, 12, 53-67. https://doi.org/10.1016/j.bodyim.2014.09.006

Ungewitter, R. (1913). Nacktheit und Kultur: neue Forderungen. 
Victora, C. G., Bahl, R., Barros, A. J., França, G. V., Horton, S., Krasevec, J., ... \& Group, T. L. B. S. (2016). Breastfeeding in the 21st century: epidemiology, mechanisms, and lifelong effect. The Lancet, 387(10017), 475-490. https://doi.org/10.1016/S0140-6736(15)01024-7

Welch, E., Birgegård, A., Parling, T., \& Ghaderi, A. (2011). Eating disorder examination questionnaire and clinical impairment assessment questionnaire: general population and clinical norms for young adult women in Sweden. Behaviour research and therapy, 49(2), 85-91.

https://doi.org/10.1016/j.brat.2010.10.010

West, K. (2018). Naked and unashamed: Investigations and applications of the effects of naturist activities on body image, self-esteem, and life satisfaction. Journal of Happiness Studies, 19(3), 677-697.

https://doi.org/10.1007/s10902-017-9846-1

World Health Organisation, (2019). Percentage of infants breastfed at age 6 months. Retrieved from

https://gateway.euro.who.int/en/indicators/hfa 616-7260-of-infants-breastfed-at-age$\underline{6-\text { months/visualizations/\#id=19721\&tab=table }}$

Wylie, K. R., \& Eardley, I. (2007). Penile size and the 'small penis syndrome'. BJU international, 99(6), 1449-1455.

https://doi.org/10.1111/j.1464-410X.2007.06806.x 


\section{Appendices}

\section{Appendix A}

\section{Multidimensional Assessment of Interoceptive Awareness (MAIA-2) Questions}

1. When I am tense, I notice where the tension is located in my body.

2. I notice when I am uncomfortable in my body.

3. I notice where in my body I am comfortable.

4. I notice changes in my breathing, such as whether it slows down or speeds up.

5. I ignore physical tension or discomfort until they become more severe.

6. I distract myself from sensations of discomfort.

7. When I feel pain or discomfort, I try to power through it.

8. I try to ignore pain

9. I push feelings of discomfort away by focusing on something

10. When I feel unpleasant body sensations, I occupy myself with something else so I don't have to feel them.

11. When I feel physical pain, I become upset.

12.I start to worry that something is wrong if I feel any discomfort.

13. I can notice an unpleasant body sensation without worrying about it.

14. I can stay calm and not worry when I have feelings of discomfort or pain.

15. When I am in discomfort or pain, I can't get it out of my mind

16. I can pay attention to my breath without being distracted by things happening around me.

17. I can maintain awareness of my inner bodily sensations even when there is a lot going on around me.

18. When I am in conversation with someone, I can pay attention to my posture.

19. I can return awareness to my body if I am distracted.

20. I can refocus my attention from thinking to sensing my body.

21. I can maintain awareness of my whole body even when a part of me is in pain or discomfort. 
22. I am able to consciously focus on my body as a whole.

23. I notice how my body changes when I am angry.

24. When something is wrong in my life, I can feel it in my body.

25. I notice that my body feels different after a peaceful experience.

26. I notice that my breathing becomes free and easy when I feel comfortable.

27. I notice how my body changes when I feel happy / joyful.

28. When I feel overwhelmed, I can find a calm place inside.

29. When I bring awareness to my body, I feel a sense of calm.

30.I can use my breath to reduce tension.

31. When I am caught up in thoughts, I can calm my mind by focusing on my body/breathing.

32. I listen for information from my body about my emotional state.

33. When I am upset, I take time to explore how my body feels.

34. I listen to my body to inform me about what to do.

35. I am at home in my body.

36. I feel my body is a safe place.

37.I trust my body sensations. 


\section{Appendix B}

Body Appreciation Scale (BAS-2) Questions

1. I respect my body.

2. I feel good about my body.

3. I feel that my body has at least some good qualities.

4. I take a positive attitude towards my body.

5. I am attentive to my body's needs.

6. I feel love for my body.

7. I appreciate the different and unique characteristics of my body.

8. My behaviour reveals my positive attitude toward my body; for example, I walk holding my head high and smiling.

9. I am comfortable in my body.

10. I feel like I am beautiful even if I am different from media images of attractive people (e.g., models, actresses/actors). 


\section{Appendix C}

\section{Eating Disorder Examination Questionnaire (EDE-Q) Questions}

1. Have you had a definite desire to have a totally flat stomach?

2. Has thinking about shape or weight made it very difficult to concentrate on things you are interested in (for example, working, following a conversation, or reading)

3. Have you had a definite fear that you might gain weight?

4. Have you felt fat?

5. Have you had a strong desire to lose weight?

6. Has your weight influenced how you think about (judge) yourself as a person?

7. Has your shape influenced how you think about (judge) yourself as a person?

8. How much would it have upset you if you had been asked to weigh yourself once a week (no more, or less, often) for the next four weeks?

9. How dissatisfied have you been with your weight?

10. How dissatisfied have you been with your shape?

11. How uncomfortable have you felt seeing your body (for example, seeing your shape in the mirror, in a shop window reflection, while undressing or taking a bath or shower)?

12. How uncomfortable have you felt about others seeing your shape or figure (for example, in communal changing rooms, when swimming, or wearing tight clothes)? 


\section{Appendix D}

Table D1

Fisher's Z Transformation, Z values based on Table 1 correlation coefficients

\begin{tabular}{|c|c|c|c|c|c|c|c|c|c|c|c|c|c|}
\hline & Variable & 1 & 2 & 3 & 4 & 5 & 6 & 7 & 8 & 9 & 10 & 11 & 12 \\
\hline 1. & Age & & & & & & & & & & & & \\
\hline 2. & Gender & 1.177 & & & & & & & & & & & \\
\hline 3. & BMI & 0.364 & -0.580 & & & & & & & & & & \\
\hline 4. & BAS-2 Body Appreciation & 0.571 & 0.094 & $2.262^{*}$ & & & & & & & & & \\
\hline 5. & EDE-Q Shape Concern & 1.481 & $-2.259^{*}$ & -0.305 & 0.298 & & & & & & & & \\
\hline 6. & EDE-Q Weight Concern & 1.526 & $-2.013^{*}$ & -0.022 & -0.242 & -0.956 & & & & & & & \\
\hline 7. & MAIA-2 Body Listening & -0.363 & 0.884 & 0.197 & $-2.997^{* *}$ & 0.043 & -0.254 & & & & & & \\
\hline 8. & $\begin{array}{l}\text { MAIA-2 Noticing } \\
\text { MAIA-2 Attention }\end{array}$ & 0.154 & 0.421 & 0.513 & -1.412 & 0.832 & 0.458 & -0.822 & & & & & \\
\hline 9. & $\begin{array}{l}\text { Regulation } \\
\text { MAIA-2 Emotional }\end{array}$ & -0.759 & 1.792 & 1.778 & -1.860 & 1.326 & 0.842 & -1.714 & -0.207 & & & & \\
\hline 10. & Awareness & 1.352 & -1.048 & 0.855 & -0.495 & 1.143 & 1.510 & -0.727 & -0.554 & 0.842 & & & \\
\hline 11. & MAIA-2 Self-Regulation & 0.388 & $2.530^{*}$ & 0.884 & 0.458 & 0.325 & 0.009 & -1.218 & 0.373 & 0.264 & -0.516 & & \\
\hline 12. & MAIA-2 Trusting & -0.085 & $2.035^{\star}$ & $3.062^{* *}$ & -0.239 & $2.193^{*}$ & 1.855 & -0.946 & 0.681 & 0.254 & 1.530 & 0.245 & \\
\hline
\end{tabular}

Note: Naturists $\mathrm{N}=43$, Controls $\mathrm{N}=36$.

${ }^{\star} p=<.05 ;{ }^{* *}=p=<.01$. 